Jonas Odermatt ${ }^{a}$, Lara Hersberger ${ }^{a}$, Rebekka Bolliger, Lena Graedel, Mirjam Christ-Crain, Matthias Briel, Heiner C. Bucher, Beat Mueller and Philipp Schuetz*

\title{
The natriuretic peptide MR-proANP predicts all-cause mortality and adverse outcome in community patients: a 10-year follow-up study
}

DOI 10.1515/cclm-2016-0760

Received August 28, 2016; accepted December 16, 2016; previously published online January 20, 2017

\begin{abstract}
Background: The precursor peptide of atrial natriuretic peptide (MR-proANP) has a physiological role in fluid homeostasis and is associated with mortality and adverse clinical outcomes in heart failure patients. Little is known about the prognostic potential of this peptide for long-term mortality prediction in community-dwelling patients. We evaluated associations of MR-proANP levels with 10-year all-cause mortality in patients visiting their general practitioner for a respiratory tract infection.

Methods: In this post-hoc analysis including 359 patients (78.5\%) of the original trial, we calculated cox regression models and area under the receiver operating characteristic curve (AUC) to assess associations of MR-proANP blood levels with mortality and adverse outcome including death, pulmonary embolism, and major adverse cardiac or cerebrovascular events.
\end{abstract}

aJonas Odermatt and Lara Hersberger contributed equally to this work. *Corresponding author: Prof. Dr. med. Philipp Schuetz, MD, MPH, Department of Endocrinology, Diabetology and Metabolism, Medical University Clinic, Kantonsspital Aarau, Tellstrasse, $\mathrm{CH}-5001$ Aarau, Switzerland; and University of Basel, Basel, Switzerland, Phone: 00416283868 12, Fax: 00416283898 73,

E-mail: schuetzph@gmail.com

Jonas Odermatt, Lara Hersberger, Rebekka Bolliger, Lena Graedel and Beat Mueller: Department of Endocrinology, Diabetology and Metabolism, Medical University Clinic, Kantonsspital Aarau, Aarau, Switzerland; and University of Basel, Basel, Switzerland

Mirjam Christ-Crain: Department of Endocrinology, Diabetology and Metabolism, Department of Clinical Research, University Hospital Basel and University of Basel, Basel, Switzerland Matthias Briel: Basel Insitute for Clinical Epidemiology \& Biostatistics, Department of Clinical Research, University Hospital Basel and University of Basel, Basel, Switzerland; and Department of Clinical Epidemiology and Biostatistics, McMaster University, Hamilton, Ontario, Canada

Heiner C. Bucher: Basel Insitute for Clinical Epidemiology \& Biostatistics, Department of Clinical Research, University Hospital Basel and University of Basel, Basel, Switzerland
Results: After a median follow-up of 10.0 years, 9.8\% of included patients died. Median admission MR-proANP levels were significantly elevated in non-survivors compared to survivors (80.5 pmol/L, IQR 58.6-126.0; vs. 45.6 $\mathrm{pmol} / \mathrm{L}, \mathrm{IQR} 34.2-68.3 ; \mathrm{p}<0.001)$ and associated with 10-year all-cause mortality (age-adjusted HR 2.0 [95\% CI 1.3-3.1, $p=0.002$ ]; AUC 0.79). Results were similar for day 7 blood levels and also for the prediction of other adverse outcomes.

Conclusions: Increased MR-proANP levels were associated with 10-year all-cause mortality and adverse clinical outcome in a sample of community-dwelling patients. If diagnosis-specific cut-offs are confirmed in future studies, this marker may help to direct preventive measures in primary care.

Keywords: all-cause mortality; atrial natriuretic peptide; general practitioner; MR-proANP; primary care.

\section{Introduction}

The use of biomarkers for risk assessment in different cardiovascular (CV), infectious and systemic diseases has gained influence during the last years [1-5]. Among promising markers, natriuretic peptides such as atrial natriuretic peptide (ANP) have emerged due to their prognostic value for poor outcomes in several $\mathrm{CV}$, metabolic and infectious diseases [6-11]. ANP is mainly produced by cardiomyocytes in the atrium of the heart and mostly known for its regulation of natriuresis and diuresis [12-14]. It has an important role in fluid homeostasis, decreases blood pressure and modulates endothelium permeability [15-18]. The secretion of ANP is triggered by several pathophysiological mechanisms such as myocyte stretch, inflammation, ischemia, fibrosis and hypertrophy of the ventricle $[19,20]$. The derivate of the precursor, the biologically active form of ANP and the biologically inactive fragments such as mid-regional pro-atrial natriuretic peptide (MR-proANP) are measurable and serve as a more reliable analyte for measurement since ANP has a short half-life of only 3-4 min [21-23]. 
Several reports found circulating MR-proANP levels to be predictive of mortality in the short- and long-term as well as other adverse outcomes, such as disease-specific complications or severity of illness and admission to the intensive care unit $[1,5,24-27]$. Previous research has focused on the association of MR-proANP levels and patients with heart failure [28-32]. Also, patients with lower respiratory tract infections have higher levels of MR-proANP as compared to healthy cohorts [27, 33]. The highest levels are found in pneumonia patients not surviving their disease [34]. Most of this research, however, focused on hospitalized patients with higher severity and data on the long-term prognostic value of MR-proANP in community-dwelling patients is still limited [35-39].

Herein, the purpose of this prospective observational 10-year follow-up was to investigate the potential of MRproANP as a prognostic biomarker for prediction of longterm all-cause mortality and adverse clinical outcomes in a general practitioner setting.

\section{Materials and methods}

\section{Study design and setting}

This 10-year post-hoc analysis of a prognostic marker is based on blood samples from a previous trial (PARTI trial) published in 2008 [40]. The design of the initial trial has been reported elsewhere (isrctn. org; Identifier: ISRCTN73182671) and a study protocol was published beforehand [41]. In brief, the randomized, multicentre, non-inferiority trial investigated effects of procalcitonin (PCT)-guided antibiotic therapy in primary care patients presenting with an acute respiratory tract infection (ARTI). Inclusion criterion was an upper or lower ARTI with physician's intention for a treatment with antibiotics. Patients were either randomized into a PCT-guided group or a standard approach group. In the PCT-guided group, the use of antibiotics was more or less strongly discouraged based on predefined PCT cut-off ranges (procalcitonin level $\geq 0.1 \mu \mathrm{g} / \mathrm{L}$ or $\leq 0.25 \mu \mathrm{g} / \mathrm{L}$ ) [42]. The control group followed evidence-based guidelines for use of antibiotics.

The Local Ethics Committee of the University Hospital Basel (EKBB) approved the trial protocol as well as the 10-year follow-up and all procedures conformed with the Declaration of Helsinki. Written informed consent was obtained from involved general practitioners and patients for the initial PARTI trial.

A similar 10-year post-hoc analysis of the prognostic biomarker copeptin, based on the same blood samples from the PARTI trial, has been published recently and showed that copeptin was associated with 10-year all-cause mortality [43].

\section{Analysis of blood biomarkers}

Blood samples of every patient were collected and stored at the central laboratory of the University Hospital in Basel. MR-proANP was measured by batch analysis in frozen $\left(-80^{\circ}\right)$ and stored leftover samples. Determination of MR-proANP plasma levels was performed by sandwich immunoassay (SERISTRA ${ }^{\circledR}$, B.R.A.H.M.S AG, Henningsdorf/Berlin, Germany) with a functional sensitivity of $11 \mathrm{pmol} / \mathrm{L}$ and a lower detection limit of $4.3 \mathrm{pmol} / \mathrm{L}$ [44].

\section{Data collection and outcomes}

The initial sample included 458 adult patients with an ARTI, of which 359 (78.4\%) could be contacted to assess long-term outcomes (see Supplemental Table 1 for difference in the overall cohort and the included patients). For the current analysis, we performed follow-up interviews with all initially involved general practitioners, patients and/or relatives based on their availability between April 2015 and August 2015. We performed an outcome assessment using systematic questionnaires. In these questionnaires, we also retrospectively asked for $\mathrm{CV}$ risk factors and comorbidities at baseline. Also, the register of deaths of the cantons Basel-Stadt and Basel-Land was consulted if no information about vital status was available.

We contacted the same general practitioners that collected the original data and 276 patients were assessed through 40 cooperating primary care physicians. Seventy-three patients and/or their relatives could be contacted by phone calls, nine patients were detected via the register of deaths of the cantons Basel-Stadt and Basel-Land and one patient died in the 28-day follow-up period of the initial trial.

Our primary outcome was 10 -year all-cause mortality. Secondary outcomes were defined as adverse outcome events including death, pulmonary embolism, and major adverse cardiac or cerebrovascular events (MACCE) including cardiac infarction, cardiac arrest, stroke and transient ischemic attack. We also looked separately at MACCE and stroke as secondary outcomes. These endpoints were assessed by self- and general practitioner-report only and assessment was blinded to MR-proANP blood levels.

\section{Statistical analysis}

Statistical analyses were performed using STATA 12.1 (STATA Corp, College Station, TX, USA).

Categorical variables are expressed as percentages (numbers) and continuous variables as medians (interquartile ranges [IQRs]), unless stated otherwise. If applicable, 95\% confidence intervals (CIs) are presented. The $\chi^{2}$ (Wald) test is used for frequency comparisons, the nonparametric (Mann-Whitney-U) test for two-sample comparisons. We used univariable, bivariable (adjusting for age) as well as a fully adjusted model (adjusting for age, gender, randomisation arm, antibiotic use initially, smoking history, comorbidities (COPD [chronic obstructive pulmonary disease], arterial hypertension, dyslipoproteinemia and diabetes) and type of infection) cox regression analysis to evaluate the association of MR-proANP with primary and secondary outcomes. We report hazard ratios (HRs) and 95\% CIs as a measure of association for time to event data and C-Statistics (area under the curve [AUC]) as a measure of discrimination. Since the distribution of raw biomarker data was skewed, we used a natural logarithm (base $e$ ) transformation. Thereafter, the distribution of the biomarker data approximated a normal distribution. HR thereby corresponds to a nearly one-fourth-unit increase in the explanatory variable and to a 2.72-fold increase in log transformed biomarker levels. Further, for illustration, we present Kaplan-Meier 
survival estimates of long-term survival by quartiles of MR-proANP levels. A post-hoc power analysis looking at mean differences in baseline MR-proANP blood levels in the two groups of 10-year survivors and 10-year non-survivors shows that our study had a power of $83 \%$ to detect the observed increase in mean MR-proANP from 57 $\mathrm{pmol} / \mathrm{L}$ (standard deviation [SD] 40) to $140 \mathrm{pmol} / \mathrm{L}$ (SD 167).

\section{Results}

\section{Baseline characteristics}

Baseline characteristics of patients who could be contacted for long-term outcomes $(\mathrm{n}=359)$ as well as stratified by 10 -year survival status are presented in Table 1 . The median age was 47.9 (IQR 34.0-63.0) and 137 (38.2\%) were male. Concerning CV risk factors at baseline, 54 (15.3\%) had a positive CV family history and 119 (33.1\%) a history of smoking, 58 (16.2\%) hypertension and dyslipoproteinemia was found in 35 patients (15.3\%).
The median blood value of MR-proANP levels measured at the day of randomization was $47.7 \mathrm{pmol} / \mathrm{L}$ (IQR 35.0-75.5; $\mathrm{n}=350$ ) and $54.7 \mathrm{pmol} / \mathrm{L}(\mathrm{IQR} 37.5-79.3 ; \mathrm{n}=334$ ) at day 7 after randomization.

\section{Primary outcome: 10 -year all-cause mortality}

During the 10.0 (IQR 9.5-10.3) years of follow-up, 35 patients (9.8\%) died. Non-survivors had higher median baseline MRproANP blood levels ( $\mathrm{pmol} / \mathrm{L}$ ) compared to survivors (80.5, IQR 58.6-126.0; vs. 45.6, IQR 34.2-68.3; p<0.001). Similarly, day 7 blood levels also showed significant differences (91.4, IQR 63.1-150.0; vs. 52.1, IQR 37.0-73.7, $\mathrm{p}<0.001$ ). To illustrate the association with the proportion of survivors, we generated Kaplan-Meier curves (Figure 1), with patients stratified based on MR-proANP blood level quartiles (Q 1-3 vs. Q 4). Mortality was increased in patients in the highest MR-proANP quartile compared to quartiles 1-3. Also, as demonstrated in Table 2, we found significant results in cox

Table 1: Baseline characteristics overall and by 10-year survival status.

\begin{tabular}{|c|c|c|c|c|}
\hline Characteristics & $\begin{array}{r}\text { Patients with long- } \\
\text { term outcomes } \\
n=359\end{array}$ & $\begin{array}{r}10 \text {-year } \\
\text { survivors } \\
n=324\end{array}$ & $\begin{array}{r}10 \text {-year } \\
\text { non-survivors } \\
n=35\end{array}$ & p-Value \\
\hline \multicolumn{5}{|l|}{ Demographic characteristics } \\
\hline Age in years, median (IQR) & $45.0(34.0,63.0)$ & $43.5(31.0,58.5)$ & $77.0(68.0,81.0)$ & $<0.001$ \\
\hline Male, n (\%) & $137(38.2 \%)$ & $116(35.8 \%)$ & $21(60.0 \%)$ & 0.005 \\
\hline \multicolumn{5}{|l|}{ CV risk factors } \\
\hline Positive family history, n (\%) & 54 (15.3\%) & $52(16.1 \%)$ & 2 (6.7\%) & 0.17 \\
\hline Smoker or former smoker, n (\%) & 119 (33.1\%) & $103(31.8 \%)$ & $16(45.7 \%)$ & 0.096 \\
\hline Pack years, median (IQR) & $20.0(2.5,40.0)$ & $20.0(3.0,35.0)$ & $47.0(2.0,76.0)$ & 0.024 \\
\hline \multicolumn{5}{|l|}{ Comorbidities } \\
\hline Overall comorbidities, n (\%) & $80(28.7 \%)$ & $64(19.8 \%)$ & $16(45.7 \%)$ & $<0.001$ \\
\hline Arterial hypertension, n (\%) & $58(16.2 \%)$ & $48(14.8 \%)$ & $10(28.6 \%)$ & 0.036 \\
\hline COPD, n (\%) & $17(4.7 \%)$ & $10(3.1 \%)$ & 7 (20.0\%) & $<0.001$ \\
\hline Dyslipoproteinemia, n (\%) & $35(9.7 \%)$ & $31(9.6 \%)$ & $4(11.4 \%)$ & 0.72 \\
\hline Diabetes, n (\%) & $10(2.8 \%)$ & $8(2.5 \%)$ & $2(5.7 \%)$ & 0.27 \\
\hline \multicolumn{5}{|l|}{ Initial clinical condition } \\
\hline Lower RTI, n (\%) & $196(54.6 \%)$ & $165(50.9 \%)$ & $31(88.6 \%)$ & $<0.001$ \\
\hline Upper RTI, n (\%) & $163(45.4 \%)$ & $159(49.1 \%)$ & $4(11.4 \%)$ & $<0.001$ \\
\hline \multicolumn{5}{|l|}{ Laboratory findings, baseline $(n=350)$} \\
\hline MR-proANP, median, pmol/L (IQR) & $47.7(35.0,75.5)$ & $45.6(34.2,68.3)$ & $80.5(58.6,126.0)$ & $<0.001$ \\
\hline \multicolumn{5}{|l|}{ Laboratory findings, at day $7(n=334)$} \\
\hline MR-proANP, median, pmol/L (IQR) & $54.7(37.5,79.3)$ & $52.1(37.0,73.7)$ & $91.4(63.1,150.0)$ & $<0.001$ \\
\hline \multicolumn{5}{|l|}{$2^{\circ}$ Outcomes (10-year follow-up) } \\
\hline Adverse outcome, n (\%) & $52(14.5 \%)$ & $17(5.2 \%)$ & $35(100.0 \%)$ & $<0.001$ \\
\hline MACCE, n (\%) & $19(5.4 \%)$ & $14(4.3 \%)$ & $5(16.7 \%)$ & 0.004 \\
\hline Myocardial infarction, n (\%) & $9(2.5 \%)$ & $5(1.5 \%)$ & $4(13.3 \%)$ & $<0.001$ \\
\hline Stroke, n (\%) & $8(2.3 \%)$ & $6(1.9 \%)$ & $2(6.7 \%)$ & 0.090 \\
\hline
\end{tabular}

Data are presented as median (IQR) or \% (no.). Comorbidities were identified based on medical record of general practitioner, patient report, or both. $p$-Values are statistically significant at $p<0.05$. Blood levels are presented in pmol/L. IQR, interquartile range (25th-75th percentiles); SD, standard deviation; CV, cardiovascular; COPD, chronic obstructive lung disease; ARTI, acute respiratory tract infection. 


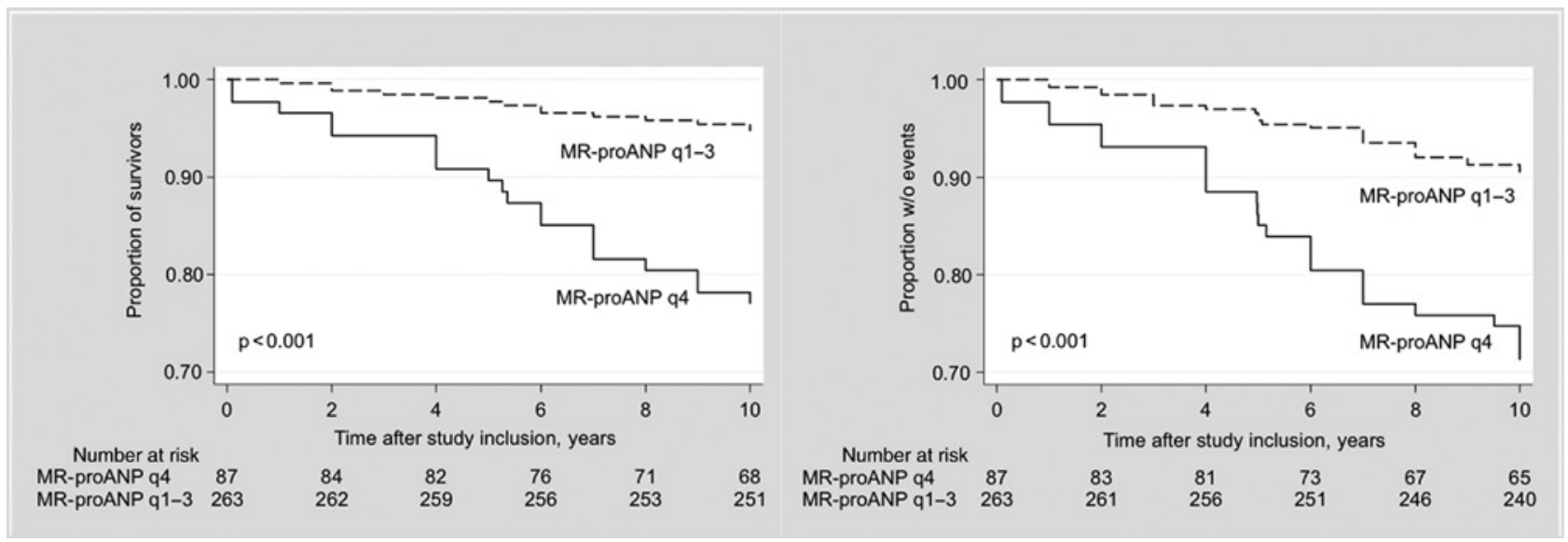

Figure 1: Ten-year Kaplan-Meier survival and without adverse outcome curve according to baseline MR-proANP blood concentration. Plots showing the association between endpoint and MR-proANP quartiles; 4th quartile vs. 1st-3rd quartile.

regression analysis where MR-proANP blood levels at baseline showed a significant association with all-cause mortality (unadjusted HR: 3.5 [95\% CI (confidence interval) 2.4-5.1, $\mathrm{p}<0.001]$; age-adjusted HR: 2.0 [95\% CI 1.3-3.1, $\mathrm{p}=0.002]$ ). The results also remained robust in a fully adjusted model including age, gender, randomisation arm, antibiotic use initially, smoking history, comorbidities and type of infection (fully adjusted model HR: 2 [95\% CI 1.2-3.3, $\mathrm{p}=0.005]$ ). Also, baseline and day 7 MR-proANP levels showed high discrimination with AUCs of 0.79 and 0.74 , respectively.

The prognostic accuracy of MR-proANP and all-cause mortality prediction in different predefined subgroups is demonstrated in Figure 2. There was no evidence for effect modification between subgroups although in nonsmokers and the younger population ( $\leq 60$ years) the prognostic accuracy of the marker tended to be stronger.

Further, we compared a clinical and demographic model, including the variables age, gender, randomisation arm, antibiotic use initially, smoking history, comorbidities and type of infection, with a model additionally including MR-proANP. Thereby, we found that MR-proANP improves the model from an AUC of 0.94 to 0.95 with a p-value of 0.067 .

We also calculated accuracy measures including sensitivity, specificity and predictive values at different MR-proANP cut-off levels (see Supplemental Table 2). As demonstrated, the optimal cut-off generated with the Youden index was at a MR-proANP value of $58.5 \mathrm{pmol} / \mathrm{L}$ at baseline and $66.2 \mathrm{pmol} / \mathrm{L}$ at day 7 .

\section{Secondary outcomes: 10 -year incidence of adverse outcome events}

Ten-year incidence of an adverse outcome, defined as death, pulmonary embolism or MACCEs, was 52 (14.5\%).
Again, MR-proANP blood levels were elevated in the patients reaching this outcome at baseline and at day 7 compared to patients not having an event. Cox regression models found associations with fair discrimination. The HRs for adverse outcome showed an association for MRproANP measurement on the day of randomization (unadjusted HR: 3.0 [95\% CI 2.1-4.3, p < 0.001]; age-adjusted HR: 1.6 [95\% CI 1.1-2.5, $\mathrm{p}=0.025]$; fully adjusted model HR: 1.5 [95\% CI 1.0-2.4, p=0.070]) (see Table 3). The analysis of most subgroups presents significant associations for the unadjusted but not for the adjusted model (see Supplemental Tables 3 and 4).

Additionally, we explored associations of MR-proANP and the different components of the adverse outcome endpoint. The unadjusted HRs showed a significant association for MR-proANP measurement on the day of randomization, but not when adjusting for age; MACCE (unadjusted HR: 2.2 [95\% CI 1.1-4.1, p=0.021], ageadjusted HR: 1.1 [95\% CI 0.5-2.4, $\mathrm{p}=0.815]$ ); myocardial infarction (unadjusted HR: 2.2 [95\% CI 1.1-4.1, $\mathrm{p}=0.021$, age-adjusted HR: 1.1 [95\% CI 0.5-2.4, $\mathrm{p}=0.815])$ and stroke (unadjusted HR: 2.4 [95\% CI 0.9-5.9, $\mathrm{p}=0.068$ ], ageadjusted HR: 1.5 [95\% CI 0.5-4.4, $\mathrm{p}=0.501]$ ) (Table 3). The specific subgroup analysis is presented in the Supplemental Material (Tables 3 and 4).

\section{Discussion}

Within this post-hoc, observational analysis of 359 patients visiting their general practitioners for a respiratory infection, we investigated the ability of a CV biomarker for longterm outcome prediction over a 10-year period. We found that MR-proANP measured during the index visit and 
Table 2: Association between MR-proANP blood levels at baseline and day 7 of follow-up and 10-year all-cause mortality.

\begin{tabular}{|c|c|c|}
\hline & & 10-year all-cause mortality \\
\hline & Baseline blood samples & Day 7 blood samples \\
\hline Overall mortality & $\mathrm{n}=34$ & $\mathrm{n}=31$ \\
\hline Unadjusted HR, p-value & $3.5(95 \% \mathrm{Cl} 2.4-5.1), \mathrm{p}<\mathbf{0 . 0 0 1}$ & $3.8(95 \% \mathrm{Cl} 2.3-6), \mathrm{p}<0.001$ \\
\hline Adjusted for age HR & $2(95 \% \mathrm{Cl} 1.3-3.1), \mathbf{p}=\mathbf{0 . 0 0 2}$ & $2.1(95 \% \mathrm{Cl} 1.2-3.7), \mathrm{p}=\mathbf{0 . 0 1 4}$ \\
\hline Fully adjusted model HR & $2(95 \% \mathrm{Cl} 1.2-3.3), \mathrm{p}=\mathbf{0 . 0 0 5}$ & $2(95 \% \mathrm{Cl} 1.1-3.7), \mathrm{p}=\mathbf{0 . 0 3 0}$ \\
\hline AUC & $0.79(95 \% \mathrm{Cl} 0.7-0.9)$ & $0.74(95 \% \mathrm{Cl} 0.6-0.8)$ \\
\hline Subgroups & & \\
\hline Gender & $\mathrm{p}^{\mathrm{a}}=0.800$ & $\mathrm{p}^{\mathrm{a}}=0.179$ \\
\hline Male & $\mathrm{n}=20$ & $\mathrm{n}=18$ \\
\hline Unadjusted HR & $3.3(95 \% \mathrm{Cl} 2-5.5), \mathrm{p}<\mathbf{0 . 0 0 1}$ & $3.2(95 \% \mathrm{Cl} 1.8-5.6), \mathrm{p}<\mathbf{0 . 0 0 1}$ \\
\hline Adjusted for age HR & $1.9(95 \% \mathrm{Cl} 1-3.4), \mathrm{p}=\mathbf{0 . 0 3 8}$ & $2.2(95 \% \mathrm{Cl} 1-4.6), \mathbf{p}=\mathbf{0 . 0 4 1}$ \\
\hline AUC & $0.81(95 \% \mathrm{Cl} 0.7-0.9)$ & $0.79(95 \% \mathrm{Cl} 0.7-0.9)$ \\
\hline Female & $\mathrm{n}=14$ & $\mathrm{n}=13$ \\
\hline Unadjusted HR & $3.5(95 \% \mathrm{Cl} 2-6.2), \mathrm{p}<0.001$ & 4 (95\% Cl 1.7-9.2), $p=0.001$ \\
\hline Adjusted for age HR & $1.9(95 \% \mathrm{Cl} 1-3.8), p=0.052$ & $1.6(95 \% \mathrm{Cl} 0.6-4), p=0.322$ \\
\hline AUC & $0.77(95 \% \mathrm{Cl} 0.7-0.9)$ & $0.67(95 \% \mathrm{Cl} 0.5-0.9)$ \\
\hline Nicotine abuse & $\mathrm{p}^{\mathrm{a}}=0.608$ & $\mathrm{p}^{\mathrm{a}}=0.896$ \\
\hline Smoker & $\mathrm{n}=15$ & $\mathrm{n}=14$ \\
\hline Unadjusted HR & $2.6(95 \% \mathrm{Cl} 1.5-4.5), \mathrm{p}=\mathbf{0 . 0 0 1}$ & $2.5(95 \% \mathrm{Cl} 1.2-5.2), \mathrm{p}=\mathbf{0 . 0 1 6}$ \\
\hline Adjusted for age HR & $1.4(95 \% \mathrm{Cl} 0.7-2.7), \mathrm{p}=0.355$ & $1.2(95 \% \mathrm{Cl} 0.5-2.9), \mathrm{p}=0.612$ \\
\hline AUC & $0.72(95 \% \mathrm{Cl} 0.6-0.9)$ & $0.67(95 \% \mathrm{Cl} 0.5-0.8)$ \\
\hline Nonsmoker & $\mathrm{n}=19$ & $\mathrm{n}=17$ \\
\hline Unadjusted HR & $4.5(95 \% \mathrm{Cl} 2.6-7.5), \mathrm{p}<0.001$ & $4.9(95 \% \mathrm{Cl} 2.7-9), \mathrm{p}<\mathbf{0 . 0 0 1}$ \\
\hline Adjusted for age HR & $2.8(95 \% \mathrm{Cl} 1.5-5.1), \mathbf{p}=\mathbf{0 . 0 0 1}$ & $3.3(95 \% \mathrm{Cl} 1.5-7.4), \mathbf{p}=\mathbf{0 . 0 0 3}$ \\
\hline AUC & $0.85(95 \% \mathrm{Cl} 0.8-0.9)$ & $0.82(95 \% \mathrm{Cl} 0.7-0.9)$ \\
\hline Age & $\mathrm{p}^{\mathrm{a}}=0.754$ & $\mathrm{p}^{\mathrm{a}}=0.488$ \\
\hline$>60$ years & $\mathrm{n}=31$ & $\mathrm{n}=28$ \\
\hline Unadjusted HR & $2(95 \% \mathrm{Cl} 1.3-3.2), \mathrm{p}=\mathbf{0 . 0 0 2}$ & $2.2(95 \% \mathrm{Cl} 1.2-4), \mathrm{p}=\mathbf{0 . 0 1 2}$ \\
\hline Adjusted for gender & $1.9(95 \% \mathrm{Cl} 1.2-3), \mathrm{p}=\mathbf{0 . 0 0 6}$ & $2(95 \% \mathrm{Cl} 1.1-3.8), \mathrm{p}=\mathbf{0 . 0 3 1}$ \\
\hline AUC & $0.65(95 \% \mathrm{Cl} 0.5-0.8)$ & $0.62(95 \% \mathrm{Cl} 0.5-0.8)$ \\
\hline$\leq 60$ years & $\mathrm{n}=3$ & $\mathrm{n}=3$ \\
\hline Unadjusted HR & $4.9(95 \% \mathrm{Cl} 1.2-20.2), \mathbf{p}=\mathbf{0 . 0 2 8}$ & $4(95 \% \mathrm{Cl} 0.9-16.8), p=0.063$ \\
\hline Adjusted for gender & $4.3(95 \% \mathrm{Cl} 1.1-17.8), p=0.041$ & $3.3(95 \% \mathrm{Cl} 0.8-13.6), p=0.096$ \\
\hline AUC & $0.89(95 \% \mathrm{Cl} 0.8-1)$ & $0.87(95 \% \mathrm{Cl} 0.8-1)$ \\
\hline
\end{tabular}

${ }^{a} \mathrm{p}$-Value for subgroup interaction. Data for univariable, bivariable and multivariable analyses are given as $\mathrm{HR}(95 \% \mathrm{Cl})$ and $\mathrm{p}$-value. Data regarding prognostic analysis are given as AUC $(95 \% \mathrm{Cl})$. A higher AUC reflects greater accuracy: 0.5 , the null value, indicates coin-toss accuracy, while 1.0, the maximum value, indicates $100 \%$ accuracy. $p$-Values in bold type are statistically significant at $p<0.05$. Univariable model includes: natural logarithmic value of MR-proANP blood concentrations. Bivariable model includes: natural logarithmic value of MRproANP blood concentrations and patient age or gender, depending on subgroup. Fully adjusted model includes: natural logarithmic value of MR-proANP blood concentrations and patient age, gender, randomisation arm, antibiotic use initially, smoking history, comorbidities and type of infection.

7 days later was a strong predictor for 10-year all-cause mortality with robust results across several subgroups. Also, MR-proANP was associated with a 10-year incidence of adverse clinical outcomes.

Previously, several observational studies found MRproANP to predict mortality and disease-specific complications. The majority of these studies, however, focused on inhospital cohorts particularly with patients after a CV event or with infections of the respiratory tract such as [1, 5-11, 24-27, 33, 45]. Two studies done by our research group found MR-ProANP to be a significant predictor for mortality and intensive care unit admission in patients with lower respiratory infection [27] and communityacquired pneumonia [33]. We also found MR-ProANP to have comparable prognostic accuracy compared to other natriuretic peptides in pneumonia patients [45]. Data of community-dwelling patients with lower severity, however, are largely lacking. Herein, this 10-year followup study closed this gap and found a strong prognostic value of this marker for mortality prediction and prediction of adverse outcome in a heterogeneous outpatientbased cohort with a respiratory tract infection. 


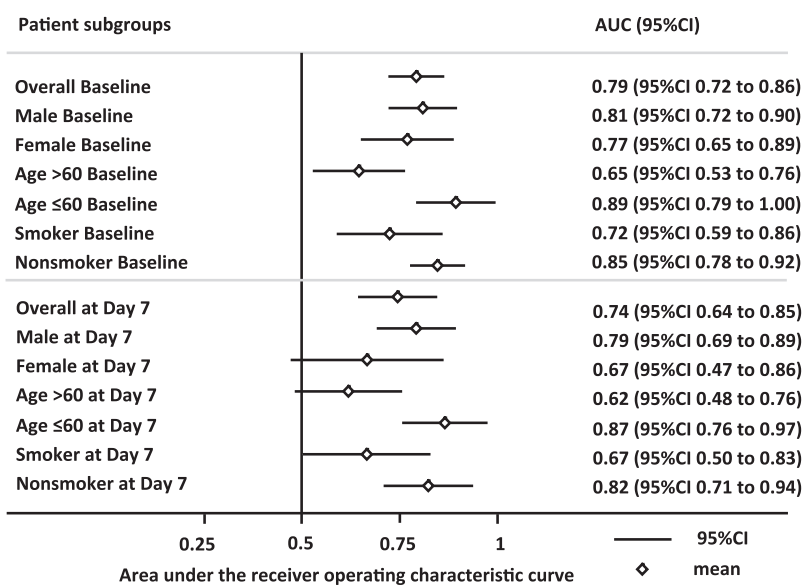

Figure 2: Forest plot of MR-proANPs prognostic accuracy in predicting 10 -year all-cause mortality at baseline and day 7 in different patients subgroups.

Müller et al. [27] showed in an emergency department setting that MR-proANP levels were significantly higher in patients with ARTI when compared with healthy controls, but they showed as well a positive association on admission with significantly higher blood levels in nonsurvivors when compared with survivors.

However, we had access to MR-proANP levels measured on admission to the general practitioners office, while patients were suffering from ARTI and 7 days later when the infection may have been cured. Interestingly, the prognostic accuracy of MR-proANP was similar for admission and day 7 levels suggesting that this marker may be used during an acute infection episode and in stable disease for long-term prognostication.

Thus, MR-proANP seems to be an early and sensitive marker for cardiac stress and may mirror both, the acute inflammatory response reflecting the severity of the acute disease and the pre-existing CV comorbidities.

As ANP influences fluid homeostasis, blood pressure and endothelial permeability $[15,16]$, it might directly raise the risk of adverse outcomes with higher blood concentrations. Evidence points to an inverse association with intima media thickness or metabolic syndrome because of inhibitory effects of obesity and lipid/glucose alterations [35], but hypertension and increased arterial stiffness are positively associated with MR-proANP levels [46]. In our study we did not perform a more in-depth assessment of comorbidities including cardiac echogram which could have given insights into the pathophysiology and explained the observed associations.

Whether MR-proANP will improve clinical decision making in the future has not been defined but is likely to require additional data showing specific treatment implications [8]. Studies point toward the potential to be useful for targeting therapies with an angiotensin-converting enzyme inhibitor in patients with stable ischemic

Table 3: Association between MR-proANP blood levels at baseline and day 7 of follow-up and 10-year poor $2^{\circ}$ outcome.

\begin{tabular}{|c|c|c|c|c|}
\hline & Adverse outcome & MACCE & Myocardial infarction & Stroke \\
\hline Overall & $\mathrm{n}=50$ & $\mathrm{n}=17$ & $\mathrm{n}=9$ & $\mathrm{n}=7$ \\
\hline Unadjusted HR & $\begin{array}{l}3(95 \% \mathrm{Cl} 2.1-4.3) \\
\mathbf{p}<0.001\end{array}$ & $\begin{array}{l}2.2(95 \% \mathrm{Cl} 1.1-4.1) \\
\mathrm{p}=\mathbf{0 . 0 2 1}\end{array}$ & $\begin{array}{l}2.6(95 \% \mathrm{Cl} 1.2-6) \\
\mathbf{p}=\mathbf{0 . 0 2 1}\end{array}$ & $\begin{array}{l}2.4(95 \% \mathrm{Cl} 0.9-5.9) \\
\mathbf{p}=\mathbf{0 . 0 6 8}\end{array}$ \\
\hline Adjusted for age HR & $\begin{array}{l}1.6(95 \% \mathrm{Cl} 1.1-2.5) \\
\mathbf{p}=\mathbf{0 . 0 2 5}\end{array}$ & $\begin{array}{l}1.1(95 \% \mathrm{Cl} 0.5-2.4) \\
p=0.815\end{array}$ & $\begin{array}{l}1.3(95 \% \mathrm{Cl} 0.5-3.6) \\
p=0.602\end{array}$ & $\begin{array}{l}1.5(95 \% \mathrm{Cl} 0.5-4.4), \\
p=0.501\end{array}$ \\
\hline Fully adjusted model HR & $\begin{array}{l}1.5(95 \% \mathrm{Cl} 1.0-2.4) \\
\mathrm{p}=0.070\end{array}$ & $\begin{array}{l}0.8(95 \% \mathrm{Cl} 0.3-2.1) \\
\mathrm{p}=0.694\end{array}$ & $\begin{array}{l}1.3(95 \% \mathrm{Cl} 0.3-5.0) \\
p=0.723\end{array}$ & $\begin{array}{l}1.1(95 \% \mathrm{Cl} 0.3-3.6) \\
p=0.917\end{array}$ \\
\hline AUC & $0.72(95 \% \mathrm{Cl} 0.6-0.8)$ & $0.63(95 \% \mathrm{Cl} 0.5-0.8)$ & $0.66(95 \% \mathrm{Cl} 0.5-0.8)$ & $0.60(95 \% \mathrm{Cl} 0.4-0.8)$ \\
\hline Overall at 7 days & $\mathrm{n}=46$ & $\mathrm{n}=17$ & $\mathrm{n}=8$ & $\mathrm{n}=7$ \\
\hline Unadjusted HR & $\begin{array}{l}2.8(95 \% \mathrm{Cl} 1.9-4.3) \\
\mathbf{p}<0.001\end{array}$ & $\begin{array}{l}2.1(95 \% \mathrm{Cl} 1-4.3) \\
\mathbf{p}=\mathbf{0 . 0 5 0}\end{array}$ & $\begin{array}{l}2.7(95 \% \mathrm{Cl} 1-7), \\
p=\mathbf{0 . 0 4 8}\end{array}$ & $\begin{array}{l}2.7(95 \% \text { Cl 1-7.5) } \\
p=0.053\end{array}$ \\
\hline Adjusted for age HR & $\begin{array}{l}1.5(95 \% \mathrm{Cl} 0.9-2.5) \\
p=0.141\end{array}$ & $\begin{array}{l}1(95 \% \mathrm{Cl} 0.5-2.4) \\
\mathrm{p}=0.916\end{array}$ & $\begin{array}{l}1.3(95 \% \mathrm{Cl} 0.4-4) \\
p=0.676\end{array}$ & $\begin{array}{l}1.7(95 \% \mathrm{Cl} 0.5-5.4), \\
p=0.386\end{array}$ \\
\hline Fully adjusted model HR & $\begin{array}{l}1.3(95 \% \mathrm{Cl} 0.8-2.2) \\
p=0.297\end{array}$ & $\begin{array}{l}0.8(95 \% \mathrm{Cl} 0.3-2.2) \\
p=0.708\end{array}$ & $\begin{array}{l}1.3(95 \% \mathrm{Cl} 0.3 \text { to } 5.4) \\
p=0.680\end{array}$ & $\begin{array}{l}1.1(95 \% \mathrm{Cl} 0.3-4.3), \\
p=0.883\end{array}$ \\
\hline AUC & $0.69(95 \% \mathrm{Cl} 0.6-0.8)$ & $0.63(95 \% \mathrm{Cl} 0.5-0.8)$ & $0.66(95 \% \mathrm{Cl} 0.5-0.9)$ & $0.65(95 \% \mathrm{Cl} 0.4-0.9)$ \\
\hline
\end{tabular}

Data for univariable, bivariable and multivariable analyses are given as $\mathrm{HR}(95 \% \mathrm{Cl})$ and $\mathrm{p}$ value. Data regarding prognostic analysis are given as AUC $(95 \% \mathrm{Cl})$. A higher AUC reflects greater accuracy: 0.5, the null value, indicates coin-toss accuracy, while 1.0, the maximum value, indicates $100 \%$ accuracy. $p$-Values in bold type are statistically significant at $p<0.05$. Univariable model includes: natural logarithmic value of MR-proANP blood concentrations. Bivariable model includes: natural logarithmic value of MR-proANP blood concentrations and patient age or gender, depending on subgroup. Fully adjusted model includes: natural logarithmic value of MR-proANP blood concentrations and patient age, gender, randomisation arm, antibiotic use initially, smoking history, comorbidities and type of infection. 
heart disease aimed at preventing adverse remodeling in patients with acute coronary syndrome. Notably, Sabatine et al. [47] presented data among patients having a MR-proANP, level in the top quartile, where an angiotensin-converting enzyme inhibitor significantly reduced the risk of $\mathrm{CV}$ death or heart failure, whereas no benefit was observed among those with lower levels. If this interaction with MR-proANP and treatment is supported by further evidence, it is possible that clinical application could be applied not only to enhance risk stratification but also to select new or established therapies i.e. to reduce the risk of heart failure after acute coronary syndrome [8].

Similarly, a previous large study (BACH) focused on patients with acute dyspnea. Based on their results, Daniels et al. [48] recommended a cut-off point of 120 $\mathrm{pmol} / \mathrm{L}$ to rule out heart failure. Although sex and BMI were associated with MR-proANP levels, these factors did not have an influence on the diagnostic performance of MR-proANP. Also, Heining et al. [49] investigated the diagnostic measures of MR-proANP for the diagnosis of heart failure at the $120 \mathrm{pmol} / \mathrm{L}$ cut-off and found high sensitivity of $91.1 \%$ and an NPV (negative predictive value) of $92.1 \%$. In the absence of atrial fibrillation, Richards et al. [50] found an optimal cut-off of $210 \mathrm{pg} / \mathrm{mL}$ for MR-proANP to rule out heart failure, which was higher in patients with atrial fibrillation $(370 \mathrm{pg} / \mathrm{mL})$.

Concerning all-cause mortality at 3 months in patients with coronary artery disease, Haehling et al. [51] found an optimal cut-off value of $236 \mathrm{pmol} / \mathrm{L}$, and in patients with heart failure, the optimal prognostic accuracy was at $295 \mathrm{pmol} / \mathrm{L}$ for 24 month survival [28].

In comparison, our study with a younger population shows a lower optimal cut-off level of $58.5 \mathrm{pmol} / \mathrm{L}$ for long-term 10-year survival (Table 2).

The result of our 10-year follow-up study is in-line with the existing literature. Especially, for the prediction of allcause mortality, MR-proANP seems to be a valid tool in the general practitioner setting as well as in the emergency department. Further, MR-proANP has the strongest predictive value in combination with correlated biomarkers, particularly brain natriuretic peptide (BNP), N-terminal pro-BNP (NT-proBNP), or midregional pro-adrenomedullin (MR-proADM) and in subanalysis even outperformed them in their accuracy $[10,28,52]$. Our results confirm the existing knowledge that MR-proANP can be regarded as third valid natriuretic peptide besides NT-proBNP and BNP. However, there are studies like Eggers et al. [36] where MR-proANP tended to show less distinct associations to left ventricular abnormalities and mortality, particularly compared to NT-proBNP.
We compared AUCs for 10-year all-cause mortality of a clinical and demographic model with a model additionally including MR-proANP and calculated that MR-proANP improves the model from an AUC of 0.94 to 0.95 with a $\mathrm{p}$-value of 0.067 . However, we believe these models are much too optimistic with a limited sensitivity of the method due to over-fitting issues and are to be treated with caution. We therefore focused on the comparison of MR-proANP with our endpoints without the clinical and demographic model.

Nonetheless, according to our analysis MR-proANP is superior to copeptin, another osmo-dependent stress and inflammatory biomarker, in mortality prediction in the primary care setting [43] (see Supplemental Table 5).

$\mathrm{CV}$ risk assessment is important for clinical practice and common risk scores, e.g. Framingham score or AGLA score, remain the standard of care for prognostication. Nevertheless, biomarkers such as MR-proANP provide further reference for mortality prediction in community patients and add an additional benefit to concomitant laboratory values and established risk scores. This in turn might result in more personalized treatment considerations thereby reducing hospitalizations or outpatient visits, and thus has the potential of reducing health care costs. In regard to the recently enhanced assay design of MR-proANP, the prognostic accuracy might have been underestimated in the last years and clinical use of this biomarker might increase [7].

The strengths of this study include the long follow-up period of 10 years, the participation of multiple primary care practices, and the sample of community-dwelling patients with respiratory tract infections representative for an outpatient population.

The following limitations require consideration: first, while the register of deaths could confirm survival status of patients, no information was available on the cause of death. Also, there is the possibility that general practitioners have not seen their patients on a regular basis, or relatives did not remember medical information. Therefore, assessment of the data was not consistent and we limited our analysis to all-cause rather than to cause-specific mortality. Second, the incomplete baseline risk assessment in the original cohort, e.g. blood parameters such as lipid values or blood pressure, do not allow us to investigate whether MR-proANP would improve state-of-the-art risk scores (e.g. Framingham risk score). It will thus be important to investigate MR-proANP in cohorts of patients with more rigorous assessment of $\mathrm{CV}$ risk factors in the future. Third, our sample was small in size. Thus we were not able to analyze further short-term adverse outcomes and the power to show significant associations with some of the outcomes is low. Lastly, our follow-up rate was $78.5 \%$. 


\section{Conclusions}

In a sample of patients visiting their general practitioner for a respiratory infection, MR-proANP was associated with 10-year all-cause mortality and adverse outcome including death, pulmonary embolism, and MACCE. These results suggest that MR-proANP could be used in future research looking at long-term prognostication in primary care patients and may also prove useful as a companion diagnostic for primary prevention measures.

Acknowledgments: We are grateful to the physicians, their staff and patients who participated in the PARTI trial and the follow-up data collection. We would also like to thank the staff of the central laboratory of the University Hospital Basel for their assistance and technical support.

Author contributions: All the authors have accepted responsibility for the entire content of this submitted manuscript and approved submission. Mr. Odermatt and Ms. Lara Hersberger contributed equally to this study. Mr. Odermatt, Ms. Hersberger and Dr. Schuetz had full access to all of the data in the study and take responsibility for the integrity of the data, performed the statistical work, and drafted the manuscript. All authors helped to interpret the findings, read and revised the manuscript critically for important intellectual content, and approved the final version of the manuscript.

Research funding: The investigator-initiated PARTI trial was sponsored by a grant from the Swiss National Science Foundation (3300C0-107772) and by the Association for the Promotion of Science and Postgraduate Training of the University Hospital Basel. B.r.a.h.m.s. AG provided assay and kit material related to the study. Dr. Schuetz and Dr. Christ-Crain were supported by funds of the Freiwillige Akademische Gesellschaft, the Department of Endocrinology, Diabetology and Clinical Nutrition, and the Department of Clinical Chemistry, all Basel, Switzerland. Drs. Christ-Crain, Mueller and Schuetz, received support from B.r.a.h.m.s. to attend meetings and fulfilled speaking engagements. Drs. Schuetz, Christ-Crain and Mueller received support from bioMérieux to attend meetings and fulfilled speaking engagements. Dr. Mueller has served as a consultant and received research support from B.r.a.h.m.s. and bioMérieux. Heiner C. Bucher has received research support from B.r.a.h.m.s.

Employment or leadership: None declared.

Honorarium: None declared.

Competing interests: The funding organization(s) played no role in the study design; in the collection, analysis, and interpretation of data; in the writing of the report; or in the decision to submit the report for publication.

\section{References}

1. Schuetz P, Wolbers M, Christ-Crain M, Thomann R, Falconnier C, Widmer I, et al. Prohormones for prediction of adverse medical outcome in community-acquired pneumonia and lower respiratory tract infections. Crit Care 2010;14:R106.

2. Schuetz P. "Personalized" sepsis care with the help of specific biomarker levels on admission and during follow up: are we there yet? Clin Chem Lab Med 2015;53:515-7.

3. Schuetz P, Hausfater P, Amin D, Amin A, Haubitz S, Faessler L, et al. Biomarkers from distinct biological pathways improve early risk stratification in medical emergency patients: the multinational, prospective, observational TRIAGE study. Crit Care 2015;19:377.

4. Kutz A, Briel M, Christ-Crain M, Stolz D, Bouadma L, Wolff M, et al. Prognostic value of procalcitonin in respiratory tract infections across clinical settings. Crit Care 2015;19:74.

5. Alan M, Grolimund E, Kutz A, Christ-Crain M, Thomann R, Falconnier C, et al. Clinical risk scores and blood biomarkers as predictors of long-term outcome in patients with communityacquired pneumonia: a 6-year prospective follow-up study. J Intern Med 2015;278:174-84.

6. Ahluwalia N, Blacher J, Szabo de Edelenyi F, Faure P, Julia C, Hercberg $S$, et al. Prognostic value of multiple emerging biomarkers in cardiovascular risk prediction in patients with stable cardiovascular disease. Atherosclerosis 2013;228:478-84.

7. Lindberg S, Jensen JS, Pedersen SH, Galatius S, Goetze JP, Mogelvang R. MR-proANP improves prediction of mortality and cardiovascular events in patients with STEMI. Eur J Prev Cardiol 2015;22:693-700.

8. O'Malley RG, Bonaca MP, Scirica BM, Murphy SA, Jarolim P, Sabatine MS, et al. Prognostic performance of multiple biomarkers in patients with non-ST-segment elevation acute coronary syndrome: analysis from the MERLIN-TIMI 36 trial (Metabolic Efficiency With Ranolazine for Less Ischemia in Non-ST-Elevation Acute Coronary Syndromes-Thrombolysis In Myocardial Infarction 36). J Am Coll Cardiol 2014;63:1644-53.

9. Gaggin HK, Januzzi JL, Jr. Natriuretic peptides in heart failure and acute coronary syndrome. Clin Lab Med 2014;34:43-58, vi.

10. Seronde MF, Gayat E, Logeart D, Lassus J, Laribi S, Boukef R, et al. Comparison of the diagnostic and prognostic values of B-type and atrial-type natriuretic peptides in acute heart failure. Int J Cardiol 2013;168:3404-11.

11. Aiura K, Ueda M, Endo M, Kitajima M. Circulating concentrations and physiologic role of atrial natriuretic peptide during endotoxic shock in the rat. Crit Care Med 1995;23:1898-906.

12. Ruiz-Gonzalez A, Esquerda A, Porcel JM, Bielsa S, Valencia H, Cao $\mathrm{G}$, et al. A pilot study on the diagnostic accuracy of proadrenomedullin and proatrial natriuretic Peptide in lower respiratory tract infections. Open Respir Med J 2014;8:22-7.

13. Reinstadler SJ, Feistritzer HJ, Klug G, Mayr A, Huybrechts L, Hammerer-Lercher A, et al. Biomarkers of hemodynamic stress and aortic stiffness after STEMI: a cross-sectional analysis. Dis Markers 2015;2015:717032. 
14. Khan SQ, Dhillon O, Kelly D, Squire IB, Struck J, Quinn P, et al. Plasma N-terminal B-Type natriuretic peptide as an indicator of long-term survival after acute myocardial infarction: comparison with plasma midregional pro-atrial natriuretic peptide: the LAMP (Leicester Acute Myocardial Infarction Peptide) study. J Am Coll Cardiol 2008;51:1857-64.

15. Katan M, Fluri F, Schuetz P, Morgenthaler NG, Zweifel C, Bingisser R, et al. Midregional pro-atrial natriuretic peptide and outcome in patients with acute ischemic stroke. J Am Coll Cardiol 2010;56:1045-53.

16. Duszyniska W, Lipinska-Gediga M, Domoslawski P, Kaiser T, Durek G, Bednarz W. [Haemorrhagic shock complicating acute pancreatitis]. Anestezjol Intens Ter 2011;43:36-9.

17. Haviv M, Haver E, Lichtstein D, Hurvitz H, Klar A. Atrial natriuretic peptide in children with pneumonia. Pediatr Pulmonol 2005;40:306-9.

18. Vesely DL. Atrial natriuretic peptide prohormone gene expression: hormones and diseases that upregulate its expression. IUBMB Life 2002;53:153-9.

19. de Bold AJ, de Bold ML. Determinants of natriuretic peptide production by the heart: basic and clinical implications. J Investig Med 2005;53:371-7.

20. Dietz JR. Mechanisms of atrial natriuretic peptide secretion from the atrium. Cardiovasc Res 2005;68:8-17.

21. Frontzek K, Fluri F, Siemerkus J, Muller B, Gass A, Christ-Crain M, et al. Isolated insular strokes and plasma MR-proANP levels are associated with newly diagnosed atrial fibrillation: a pilot study. PLoS One 2014;9:e92421.

22. van Hateren KJ, Landman GW, Kleefstra N, Groenier KH, Struck J, Navis GJ, et al. The midregional fragment of pro-A-type natriuretic peptide, blood pressure, and mortality in a prospective cohort study of patients with type 2 diabetes (ZODIAC-25). Diabetes Care 2013;36:1347-52.

23. Buckley MG, Marcus NJ, Yacoub MH. Cardiac peptide stability, aprotinin and room temperature: importance for assessing cardiac function in clinical practice. Clin Sci (Lond) 1999;97:689-95.

24. Guertler C, Wirz B, Christ-Crain M, Zimmerli W, Mueller B, Schuetz P. Inflammatory responses predict long-term mortality risk in community-acquired pneumonia. Eur Respir J 2011;37:1439-46.

25. Kruger S, Ewig S, Kunde J, Hartmann O, Suttorp N, Welte T, et al. Pro-atrial natriuretic peptide and pro-vasopressin for predicting short-term and long-term survival in community-acquired pneumonia: results from the German Competence Network CAPNETZ. Thorax 2010;65:208-14.

26. Kruger S, Papassotiriou J, Marre R, Richter K, Schumann C, von Baum H, et al. Pro-atrial natriuretic peptide and provasopressin to predict severity and prognosis in communityacquired pneumonia: results from the German competence network CAPNETZ. Intensive Care Med 2007;33:2069-78.

27. Muller B, Suess E, Schuetz P, Muller C, Bingisser R, Bergmann A, et al. Circulating levels of pro-atrial natriuretic peptide in lower respiratory tract infections. J Intern Med 2006;260:568-76.

28. von Haehling S, Jankowska EA, Morgenthaler NG, Vassanelli C, Zanolla L, Rozentryt $\mathrm{P}$, et al. Comparison of midregional proatrial natriuretic peptide with $\mathrm{N}$-terminal pro-B-type natriuretic peptide in predicting survival in patients with chronic heart failure. J Am Coll Cardiol 2007;50:1973-80.

29. Moertl D, Berger R, Struck J, Gleiss A, Hammer A, Morgenthaler $N G$, et al. Comparison of midregional pro-atrial and B-type natriuretic peptides in chronic heart failure: influencing factors, detection of left ventricular systolic dysfunction, and prediction of death. J Am Coll Cardiol 2009;53:1783-90.

30. Miller WL, Hartman KA, Grill DE, Struck J, Bergmann A, Jaffe AS. Serial measurements of midregion proANP and copeptin in ambulatory patients with heart failure: incremental prognostic value of novel biomarkers in heart failure. Heart 2012;98:389-94.

31. Alehagen U, Dahlstrom U, Rehfeld JF, Goetze JP. Pro-A-type natriuretic peptide, proadrenomedullin, and $\mathrm{N}$-terminal pro-B-type natriuretic peptide used in a multimarker strategy in primary health care in risk assessment of patients with symptoms of heart failure. J Card Fail 2013;19:31-9.

32. Zabarovskaja S, Hage C, Linde C, Daubert JC, Donal E, Gabrielsen A, et al. Adaptive cardiovascular hormones in a spectrum of heart failure phenotypes. Int J Cardiol 2015;189:6-11.

33. Vazquez M, Jockers K, Christ-Crain M, Zimmerli W, Muller B, Schuetz P. MR-pro-atrial natriuretic peptide (MR-proANP) predicts short- and long-term outcomes in respiratory tract infections: a prospective validation study. Int J Cardiol 2012;156:16-23.

34. Kruger S, Ewig S, Giersdorf S, Hartmann O, Suttorp N, Welte T, et al. Cardiovascular and inflammatory biomarkers to predict short- and long-term survival in community-acquired pneumonia: Results from the German Competence Network, CAPNETZ. Am J Respir Crit Care Med 2010;182:1426-34.

35. Then C, Kowall B, Lechner A, Meisinger C, Heier M, Koenig W, et al. Plasma MR-proANP levels are associated with carotid intima-media thickness in the general community: the KORA F4 study. Atherosclerosis 2013;230:235-41.

36. Eggers KM, Venge P, Lind L. Mid-regional pro-atrial natriuretic peptide levels in the elderly: clinical and prognostic implications, and comparison to B-type natriuretic peptides. Clin Chim Acta 2013;419:62-6.

37. Hobbelt AH, Siland JE, Geelhoed B, Van Der Harst P, Hillege HL, Van Gelder IC, et al. Clinical, biomarker, and genetic predictors of specific types of atrial fibrillation in a community-based cohort: data of the PREVEND study. Europace 2016 Mar 7. pii: euw016. [Epub ahead of print].

38. Melander O, Newton-Cheh C, Almgren P, Hedblad B, Berglund G, Engstrom G, et al. Novel and conventional biomarkers for prediction of incident cardiovascular events in the community. J Am Med Assoc 2009;302:49-57.

39. van Hateren KJ, Alkhalaf A, Kleefstra N, Groenier KH, de Jong PE, de Zeeuw D, et al. Comparison of midregional pro-A-type natriuretic peptide and the $\mathrm{N}$-terminal pro-B-type natriuretic peptide for predicting mortality and cardiovascular events. Clin Chem. 2012;58:293-7.

40. Briel M, Schuetz P, Mueller B, Young J, Schild U, Nusbaumer C, et al. Procalcitonin-guided antibiotic use vs a standard approach for acute respiratory tract infections in primary care. Arch Intern Med 2008;168:2000-7; discussion 7-8.

41. Briel M, Christ-Crain M, Young J, Schuetz P, Huber P, Periat $P$, et al. Procalcitonin-guided antibiotic use versus a standard approach for acute respiratory tract infections in primary care: study protocol for a randomised controlled trial and baseline characteristics of participating general practitioners [ISRCTN73182671]. BMC Fam Pract 2005;6:34.

42. Schuetz P, Chiappa V, Briel M, Greenwald JL. Procalcitonin algorithms for antibiotic therapy decisions: a systematic review of randomized controlled trials and recommendations for clinical algorithms. Arch Intern Med 2011;171:1322-31. 
43. Odermatt J, Bolliger R, Hersberger L, Ottiger M, Christ-Crain $M$, Briel $M$, et al. Copeptin predicts 10-year all-cause mortality in community patients: a 10-year prospective cohort study. Clin Chem Lab Med 2016;54:1681-90.

44. Morgenthaler NG, Struck J, Thomas B, Bergmann A. Immunoluminometric assay for the midregion of pro-atrial natriuretic peptide in human plasma. Clin Chem 2004;50:234-6.

45. Nowak A, Breidthardt T, Christ-Crain M, Bingisser R, Meune C, Tanglay $Y$, et al. Direct comparison of three natriuretic peptides for prediction of short- and long-term mortality in patients with community-acquired pneumonia. Chest 2012;141:974-82.

46. Saritas T, Tascilar E, Abaci A, Yozgat Y, Dogan M, Dundaroz R, et al. Importance of plasma N-terminal pro B-type natriuretic peptide, epicardial adipose tissue, and carotid intima-media thicknesses in asymptomatic obese children. Pediatr Cardiol 2010;31:792-9.

47. Sabatine MS, Morrow DA, de Lemos JA, Omland T, Sloan S, Jarolim P, et al. Evaluation of multiple biomarkers of cardiovascular stress for risk prediction and guiding medical therapy in patients with stable coronary disease. Circulation 2012;125:233-40.

48. Daniels LB, Clopton P, Potocki M, Mueller C, McCord J, Richards $M$, et al. Influence of age, race, sex, and body mass index on interpretation of midregional pro atrial natriuretic peptide for the diagnosis of acute heart failure: results from the BACH multinational study. Eur J Heart Fail 2012;14:22-31.

49. Heining L, Giesa C, Ewig S. MR-proANP, MR-proADM, and PCT in Patients Presenting with Acute Dyspnea in a Medical Emergency Unit. Lung 2016;194:185-91.

50. Richards M, Di Somma S, Mueller C, Nowak R, Peacock WF, Ponikowski P, et al. Atrial fibrillation impairs the diagnostic performance of cardiac natriuretic peptides in dyspneic patients: results from the BACH Study (Biomarkers in ACute Heart Failure). JACC Heart Fail 2013;1:192-9.

51. von Haehling S, Papassotiriou J, Hartmann O, Doehner W, Stellos K, Geisler T, et al. Mid-regional pro-atrial natriuretic peptide as a prognostic marker for all-cause mortality in patients with symptomatic coronary artery disease. Clin Sci (Lond) 2012;123:601-10.

52. Lainscak M, von Haehling S, Anker SD. Natriuretic peptides and other biomarkers in chronic heart failure: from BNP, NT-proBNP, and MR-proANP to routine biochemical markers. Int J Cardiol 2009;132:303-11.

Supplemental Material: The online version of this article (DOI: 10.1515/cclm-2016-0760) offers supplementary material, available to authorized users. 